\title{
Genotype by heat stress interactions for production and functional traits in dairy cows from an across-generation perspective
}

\author{
C. Kipp, K. Brügemann, T. Yin, K. Halli, and S. König* \\ Institute of Animal Breeding and Genetics, Justus-Liebig-University Gießen, 35390 Gießen, Germany
}

\begin{abstract}
The aim of this study was to analyze time-lagged heat stress (HS) effects during late gestation on genetic co(variance) components in dairy cattle across generations for production, female fertility, and health traits. The data set for production and female fertility traits considered 162,492 Holstein Friesian cows from calving years 2003 to 2012 , kept in medium-sized family farms. The health data set included 69,986 cows from calving years 2008 to 2016, kept in participating large-scale co-operator herds. Production traits were milk yield (MKG), fat percentage (fat\%), and somatic cell score (SCS) from the first official test-day in first lactation. Female fertility traits were the nonreturn rate after $56 \mathrm{~d}$ (NRR56) in heifers and the interval from calving to first insemination (ICFI) in first-parity cows. Health traits included clinical mastitis (MAST), digital dermatitis (DD), and endometritis (EM) in the early lactation period in first-parity cows. Meteorological data included temperature and humidity from public weather stations in closest herd distance. The HS indicator was the temperature-humidity index (THI) during dams' late gestation, also defined as in utero HS. For the genetic analyses of production, female fertility, and health traits in the offspring generation, a sire-maternal grandsire random regression model with Legendre polynomials of order 3 for the production and of order 2 for the fertility and health traits on prenatal THI, was applied. All statistical models additionally considered a random maternal effect. THI from late gestation (i.e., prenatal climate conditions), influenced genetic parameter estimates in the offspring generation. For MKG, heritabilities and additive genetic variances decreased in a wave-like pattern with increasing THI. Especially for THI $>58$, the decrease was very obvious with a minimal heritability of 0.08 . For fat $\%$ and SCS, heritabilities increased slightly subjected to prenatal HS
\end{abstract}

Received February 1, 2021.

Accepted April 26, 2021.

*Corresponding author: sven.koenig@agrar.uni-giessen.de conditions at THI $>67$. The ICFI heritabilities differed marginally across THI [heritability $\left(\mathrm{h}^{2}\right)=0.02-0.04$ ]. For NRR56, MAST, and DD, curves for heritabilities and genetic variances were U-shaped, with largest estimates at the extreme ends of the THI scale. For EM, heritability increased from THI $25\left(\mathrm{~h}^{2}=0.13\right)$ to THI $71\left(\mathrm{~h}^{2}=0.39\right)$. The trait-specific alterations of genetic parameters along the THI gradient indicate pronounced genetic differentiation due to intrauterine HS for NRR56, MAST, DD, and EM, but decreasing genetic variation for MKG and ICFI. Genetic correlations smaller than 0.80 for NRR56, MAST, DD, and EM between THI 65 with corresponding traits at remaining THI indicated genotype by environment interactions. The lowest genetic correlations were identified when considering the most distant THI. For MKG, fat\%, SCS, and ICFI, genetic correlations throughout were larger than 0.80, disproving concerns for any genotype by environment interactions. Variations in genetic (co) variance components across prenatal THI may be due to epigenetic modifications in the offspring genome, triggered by in utero HS. Epigenetic modifications have a persistent effect on phenotypic responses, even for traits recorded late in life. However, it is imperative to infer the underlying epigenetic mechanisms in ongoing molecular experiments.

Key words: prenatal heat stress, across-generation analyses, genetic parameters, genotype by environment interactions

\section{INTRODUCTION}

Direct heat stress (HS) has detrimental effects on primary and functional traits in dairy cows (Oseni et al., 2003; Brügemann et al., 2011; Gernand et al., 2019). Changing genetic parameters, genotype by environment interactions $(\mathbf{G} \times \mathbf{E})$, and alterations of EBV along climate descriptors, mostly implying animal re-rankings, were observed for several cow traits (e.g., Brügemann et al., 2011; Bohlouli et al., 2019). Random regression models (RRM) or reaction norm models can be used to infer genetic (co)variances on a continuous temperature-humidity index (THI) scale, with pos- 
sible genetic correlation estimates for a broad grid of THI combinations (Aguilar et al., 2009; Santana et al., 2016).

The most popular example for the effect of a challenging maternal environment on the phenotypes in the following generation was observed during the Second World War (Frésard et al., 2013), where prenatal famine in humans resulted in epigenetic modifications and chronic diseases in their offspring (Heijmans et al., 2008). In dairy cattle, there is evidence that HS during late gestation induced carry-over effects (i.e., longlasting effects on traits recorded in offspring). In this regard, birth weight, BW up to 1 yr of age, calf immune functions, productivity, female fertility, and longevity in the offspring generation were affected (Tao et al., 2012; Monteiro et al., 2016; Kipp et al., 2021). Laporta et al. (2020) reported impairments regarding productivity and survival to first breeding in the $\mathrm{F}_{2}$ generation of heat-stressed grandmothers. Biological explanations in this regard are metabolic adaptions due to HSinduced malnourishment of the fetus in utero (Bell et al., 1989; Regnault et al., 2007; Tao and Dahl, 2013). Tao et al. (2014) observed enhanced whole-body insulin response in 55-d-old calves due to thermal stress during the dams' dry period. In ovine, Chen et al. (2010) observed that a HS-induced placental insufficiency causes a downregulation of $\beta 2$-adrenergic receptors, resulting in reduced adrenergic stimulated lipolysis and obesity. Because fetal body temperature also increases under maternal HS (Faurie et al., 2001), a direct unfavorable effect of HS on the development of fetal tissue is a further explanation in this regard (Bell et al., 1989).

Genetically, evidence of time-lagged $\mathrm{G} \times \mathrm{E}$ exist (i.e., differences in genotype responses due to in utero HS in dams). In dairy cattle, Menéndez-Buxadera et al. (2020) proved $\mathrm{G} \times \mathrm{E}$ due to HS during the last $60 \mathrm{~d}$ of gestation for milk production in the ongoing lactation of the dam itself. Genetic correlation estimates were lower than 0.50 for test-day milk yield when considering temperate and hot environments during late gestation. From an across-generation perspective, G $\times \mathrm{E}$ were observed in beef cattle. Hay and Roberts (2018) reported changing genetic parameters and $\mathrm{G} \times$ $\mathrm{E}$ for weight gain, weight, and meat quality traits in beef cattle offspring, depending on the prenatal conditions. The prenatal conditions especially considered different maternal feeding aspects (e.g., a marginal or an adequate level of protein supplementation during gestation).

Against this background, we hypothesize time-lagged HS effects on genetic co(variance) components in dairy cattle across generations. In consequence, the specific objective of the present study was to estimate genetic parameters for production, female fertility, and health traits as a function of THI from the last week of gestation. Specific focus was on the detection of possible $\mathrm{G}$ $\times \mathrm{E}$, based on genetic correlation estimates from RRM between same traits at different late-gestation THI.

\section{MATERIALS AND METHODS}

\section{Cow Traits}

The data set for production and female fertility traits (data set 1) considered all registered Holstein cows from the German federal state of Hesse from calving years 2003 to 2012. Data from herds with less than 10 cows were excluded. Additionally, cows with an age at first calving lower than 20 mo or higher than 40 mo were excluded from the ongoing analyses. Trait selection based on previous across-generation phenotypic association analyses (Kipp et al., 2021). Traits, which were significantly affected by intrauterine HS, were chosen for the present genetic study. In consequence, production traits of interest in this genetic study were milk yield (MKG), fat percentage (fat\%), and SCS from the first official test-day of the first lactation. According to Ali and Shook (1980), SCS was calculated as SCS = $\log _{2}(\mathrm{SCC} / 100,000)+3$. We focused on the first official test-day, because this period is the most challenging period for dairy cows with regard to the negative nutrient balance (De Vries et al., 1999), causing health problems in the ongoing lactation (Shabalina et al., 2020). Female fertility traits were the nonreturn rate after 56 d (NRR56) in heifers (before the first calving) defined as a binary trait (pregnant $=1$; nonpregnant $=0$ ), and the interval from calving to first insemination (ICFI) in first-parity cows as a Gaussian trait.

The health data set (data set 2) contained firstparity Holstein cows from large-scale co-operator herds located in the German federal states of MecklenburgWest Pomerania and Berlin-Brandenburg from calving years 2008 to 2016 . In family farms from data set 1 , we noticed a quite poor recording of disease diagnoses, stimulating us to use the comprehensive health data from the co-operator herds located in the eastern part of Germany. Especially for diseases with low incidences, the large contemporary groups as prevalent in these herds are imperative for unbiased genetic evaluations. The genetic architecture of the subpopulations from data sets 1 and 2 were very similar according to genetic and genomic herd characteristics (Yin and König, 2018). Veterinarians and the herd manager recorded health data based on the hierarchical diagnosis key developed by the International Committee for Animal Recording (Stock et al., 2013). Health traits included 
3 diseases from the overall categories mastitis, claw disorders, and puerperal disorders in first-parity cows. In this regard, we selected the diseases with the largest disease incidences according to Shabalina et al. (2020). These were clinical mastitis (MAST) recorded in the period from $-10 \mathrm{~d}$ before to $200 \mathrm{~d}$ after calving, the claw disorder digital dermatitis (DD) recorded in the period from $-10 \mathrm{~d}$ before to $200 \mathrm{~d}$ after calving, and the puerperal disorder endometritis (EM) recorded in the period from $-10 \mathrm{~d}$ to $30 \mathrm{~d}$ after calving in firstparity cows. At least one entry for a disease diagnosis within the defined period implied a score $=1=$ diseased for the respective disease; otherwise, the score = $0=$ healthy was assigned. Descriptive statistics for all cow traits are given in detail in Table 1.

\section{Meteorological Data}

Meteorological data included temperature and humidity from public weather stations. Herds and weather stations were merged according to their closest geographical distance. In this regard, we applied the R-package Geosphere (Hijmans et al., 2016). The distance between the herds and the weather stations ranged between 7.99 and $36.27 \mathrm{~km}$. Based on daily averages for temperature $\left(\mathbf{T}\right.$; in $\left.{ }^{\circ} \mathrm{C}\right)$ and relative humidity (RH; in \%), the daily THI was calculated as follows (NRC, 1971):

$$
\begin{aligned}
& \mathrm{THI}=(1.8 \times \mathrm{T}+32)-(0.55-0.0055 \times \mathrm{RH}) \\
& \times(1.8 \times \mathrm{T}-26) .
\end{aligned}
$$

For example, a temperature of $20^{\circ} \mathrm{C}\left(68^{\circ} \mathrm{F}\right)$ implies a THI of 63 (for $\mathrm{RH}=0 \%$ ) to 68 (for $\mathrm{RH}=100 \%$ ), or for a temperature of $30^{\circ} \mathrm{C}$, THI ranges from 71 to 86 depending on RH.

In previous phenotypic association analyses, the last week before birth (d 0-7 before birth) was identified as the period with the strongest time-lagged sensitivity to intrauterine HS (Kipp et al., 2021). Therefore, in the present study, the THI during the last week of gestation was considered as HS indicator, also defined as intrauterine HS. Records at both extreme ends of the THI scale with small observation numbers per THI were discarded (threshold: at least 100 observations per THI), implying to narrow the THI range based on trait distributions. Afterward, the THI ranged from 20 to 73 for MKG, fat\%, and SCS, from 21 to 72 for NRR56 and ICFI, and from 20 to 71 for MAST, DD, and EM. The distribution of records by THI for MKG is shown in Figure 1. Distributions for all other traits were very similar.
Table 1. Descriptive statistics for production traits from the first official test-day, female fertility traits, and health traits recorded in offspring $^{1}$

\begin{tabular}{lrrrr}
\hline Trait & $\begin{array}{c}\text { No. of heifers } \\
\text { or cows }\end{array}$ & Mean & SD & $\begin{array}{c}\text { No. of } \\
\text { herds }\end{array}$ \\
\hline Milk yield (kg) & 162,492 & 26.42 & 5.83 & 1,964 \\
Fat percentage (\%) & 160,866 & 4.21 & 0.79 & 1,964 \\
SCS (SCS/mL) & 162,373 & 2.86 & 1.73 & 1,964 \\
NRR56 (\%) & 80,230 & 76.47 & 42.41 & 1,019 \\
ICFI (d) & 128,631 & 90.77 & 42.12 & 1,713 \\
MAST & 69,986 & 0.22 & 0.41 & 64 \\
DD & 67,252 & 0.10 & 0.30 & 60 \\
EM & 52,012 & 0.08 & 0.28 & 46 \\
\hline
\end{tabular}

${ }^{1} \mathrm{NNR} 56=$ nonreturn rate after $56 \mathrm{~d}$; ICFI $=$ interval from calving to first insemination; MAST $=$ clinical mastitis; $\mathrm{DD}=$ digital dermatitis; $\mathrm{EM}=$ endometritis.

\section{Statistical Models}

In an animal model, the single cow only has one observation for one specific THI, probably causing failure in convergence in complex RRM. Consequently, for genetic analyses, a single-trait sire-maternal grandsire RRM with maternal effects was applied. Random regressions were modeled through Legendre polynomials on time-lagged THI (i.e., THI during the last week before birth in the fetal stage). In matrix notation, the statistical model was defined as follows:

$$
\mathbf{y}=\mathbf{X b}+\mathbf{Z u}+\mathbf{W m}+\mathbf{e}
$$

where $\mathbf{y}=$ vector of observations for Gaussian distributed test-day records (MKG, fat\%, and SCS) and ICFI, and binary observations for NRR56, MAST, DD, and EM; $\mathbf{b}=$ vector of fixed effects including herd, calving year, calving month, DIM, age at first calving, and regressions on THI during the last week of dams' gestation using third-order Legendre polynomials for the production traits (MKG, fat\%, and SCS), including herd, year of insemination, month of insemination, age at insemination, and regressions on THI during the last week of dams' gestation using second-order Legendre polynomials for female fertility traits (NRR56 and ICFI), and including herd, calving year, calving month, age at first calving, and regressions on THI during the last week of dams' gestation using second-order Legendre polynomials for the health traits (MAST, DD, and $\mathrm{EM}) ; \mathbf{u}=$ vector of random regression coefficients for sire effects using Legendre polynomials of order 3 for the production traits, and of order 2 for the female fertility and the health traits; $\mathbf{m}=$ vector of random maternal effects; and $\mathbf{e}=$ vector of random residual effects; and $\mathbf{X}, \mathbf{Z}$, and $\mathbf{W}$ are the incidence matrices for $\mathbf{b}, \mathbf{u}$, and $\mathbf{m}$, respectively. For NRR56, an additional 


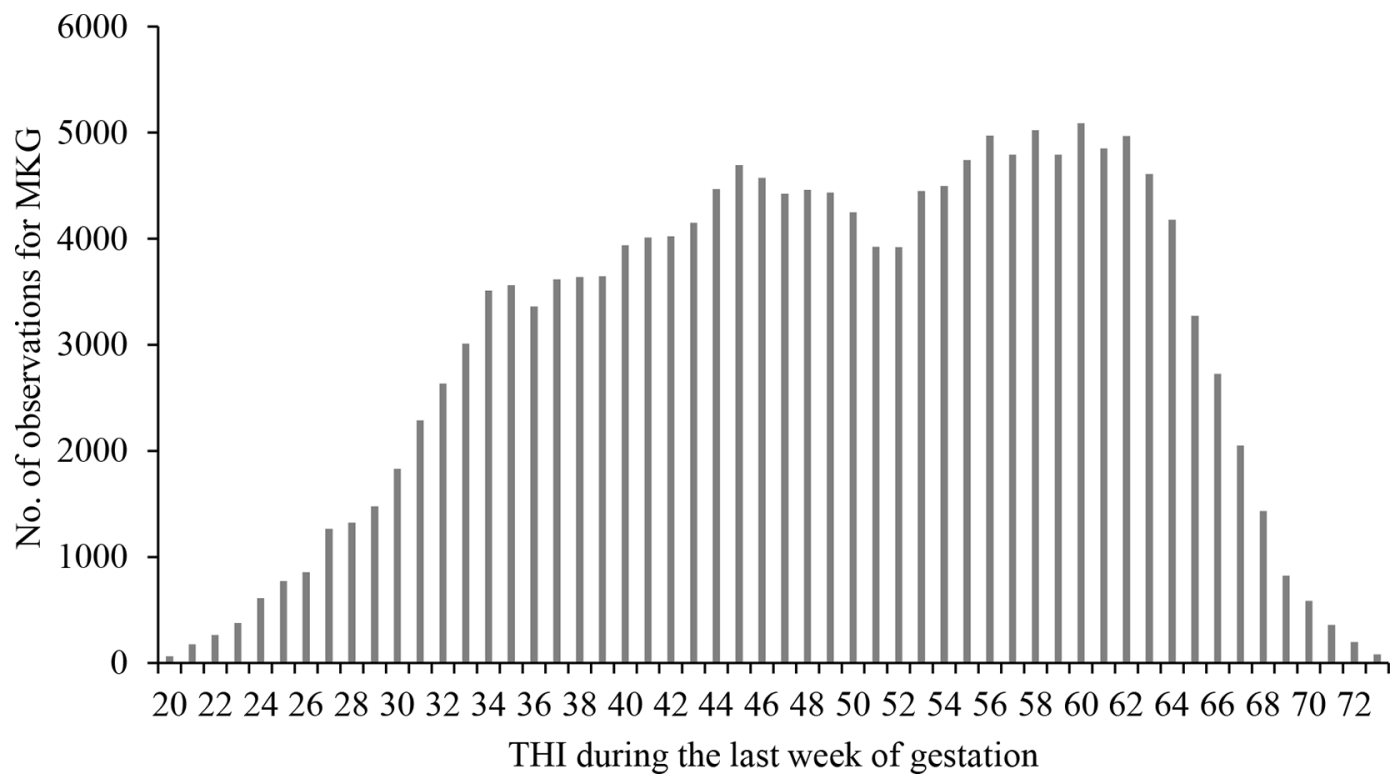

Figure 1. Distribution of records for milk yield (MKG) by temperature-humidity index (THI) during the last week of gestation of the respective dam.

vector $\mathbf{s}$ for the random service sire effects and a respective incidence matrix $\mathbf{S}$ were considered. The random maternal effect reflects the broad spectrum of the damspecific environment. Each dam had on average 1.34 female offspring with trait records.

For all traits except NRR56, the variance-covariance structure for the random effects was assumed as

$$
\mathbf{v a r}\left[\begin{array}{c}
\mathbf{u} \\
\mathbf{m} \\
\mathbf{e}
\end{array}\right]=\left(\begin{array}{ccc}
\mathbf{G} \otimes \mathbf{A}_{\mathbf{u}} & 0 & 0 \\
0 & \mathbf{M} \otimes \mathbf{I}_{\mathbf{m}} & 0 \\
0 & 0 & \mathbf{R} \otimes \mathbf{I}_{\mathbf{n}}
\end{array}\right)
$$

where $\mathbf{G}=$ additive genetic (co)variance matrix for random regression coefficients of cow sire effects, $\mathbf{A}_{\mathbf{u}}=$ additive genetic relationship matrix among cow sires, $\mathbf{M}=$ (co)variance matrix for random maternal effects, $\mathbf{I}_{\mathbf{m}}=$ is the identity matrix for $m$ dams, $\mathbf{R}=$ (co)variance matrix for random residual effects, $\mathbf{I}_{\mathbf{n}}=$ identity matrix for $n$ observations, and $\otimes=$ Kronecker product.

For NRR56, the variance-covariance structure of the random effects was assumed as

$$
\operatorname{var}\left[\begin{array}{c}
\mathbf{u} \\
\mathbf{s} \\
\mathbf{e}
\end{array}\right]=\left(\begin{array}{cccc}
\mathbf{G} \otimes \mathbf{A}_{\mathbf{u}} & 0 & 0 & 0 \\
0 & \mathbf{M} \otimes \mathbf{I}_{\mathbf{m}} & 0 & 0 \\
0 & 0 & \mathbf{S} \otimes \mathbf{I}_{\mathbf{s}} & 0 \\
0 & 0 & 0 & \mathbf{R} \otimes \mathbf{I}_{\mathbf{n}}
\end{array}\right),
$$

where $\mathbf{S}=\left(\right.$ co)variance matrix for service sire effects, $\mathbf{I}_{\mathrm{s}}$ $=$ identity matrix for $s$ service sires, and the remaining (co)variance matrices as defined above.

For the binary traits (NRR56, MAST, DD, and EM), a threshold liability model was applied, assuming residual variances equal to 1 . Hence, genetic parameters for binary traits were estimated on the underlying liability scale.

We used a Gibbs sampler (rjmc module) as implemented in the software package DMU (Madsen and Jensen, 2013). A total of 100,000 Gibbs samples were run, whereof the first 30,000 iterations were discarded as burn-in. Afterward, every 10th sample was used for post-Gibbs analyses. The length of the "burn-in period" and the sampling period was based on visual inspections for the trajectory of genetic covariances among sire effects.

\section{RESULTS}

\section{Heritabilities and Additive Genetic Variances by THI During Late Gestation}

Figure 2 displays the posterior means for heritability estimates for production traits in offspring across THI during the last week of dams' gestation. For first test-day MKG, heritability estimates ranged between 0.08 and 0.14 . From THI 33 to 58 , heritabilities slightly increased, but substantially declined for THI $>58$. Heritability estimates for fat $\%$ across THI were in nar- 
row range from 0.13 to 0.17 , and for SCS from 0.07 to 0.10 . For both traits fat $\%$ and SCS, heritabilities slightly increased under HS conditions for THI $>67$.

Figure 3 displays the posterior means for heritability estimates for female fertility traits in offspring by THI during the last gestation week of their dams. For NRR56, the heritability curve was U-shaped, displaying increased heritabilities with respect to high and low THI during late gestation. The NRR56 heritabilities ranged from 0.02 to 0.12 . Especially for NRR56, posterior standard deviation (SD) of heritabilities increased (up to 0.06) at the extreme ends of the THI scale. For ICFI, heritability differed marginally across THI (i.e., from 0.02 to 0.04 ). Smallest heritabilities were estimated at the extreme ends of the THI scale.

Figure 4 displays the posterior means for heritability estimates for health traits in offspring by THI recorded during the last week of dams' gestation. For MAST, heritability estimates were in a narrow range from 0.14 to 0.18 with highest estimates at both extreme ends of the THI scale. Heritability estimates for DD gradually decreased with increasing THI up to THI 59, displaying the smallest heritability (0.19) at THI 59. For EM, heritabilities decreased from THI 20 to 25 with the lowest value of 0.13 at THI 25. Afterward, we observed increasing EM heritabilities with increasing THI, displaying the largest estimate of 0.39 at THI 71 .

Additive genetic variances for all traits are shown in Supplemental Figure 1A to $1 \mathrm{H}$ (https://jlupub.ub .uni-giessen.de//handle/jlupub/57). Curve patterns for posterior heritabilities and posterior additive ge- netic variances were very similar. For MKG, additive genetic variances displayed a wave-shaped pattern, and by trend, decreased with increasing THI. Genetic variances for fat\% were quite stable along the continuous THI scale. For SCS, the curve for additive genetic variance was wave-shaped, displaying largest estimates at both ends of the THI scale. For ICFI, additive genetic variances were smallest at both ends of the THI scale. The pattern of the genetic variances for NRR56, MAST, and DD were U-shaped. Genetic variances for EM were smallest in the interval from THI 20 to 25, and afterward, genetic variances gradually increased with increasing THI.

\section{Genetic Correlations Between Same Traits from Different THI}

Figure 5 displays the posterior means for genetic correlations for MKG, fat\%, and SCS in the offspring generation at THI 65 with corresponding traits at remaining THI during the last week of the dam's gestation. For MKG and fat\%, genetic correlations between same traits from different THI were quite large in the range from 0.92 to 1 . Genetic correlation curve pattern were very similar for both traits, and overlapped largely. For MKG and fat\%, genetic correlations were smallest when considering records from THI 65 and records representing either prenatal cold or HS conditions. Nevertheless, the estimates throughout larger than 0.92 disprove any indications for time-lagged $\mathrm{G} \times \mathrm{E}$. For SCS, genetic correlations ranged between 0.86 and 1 . The genetic

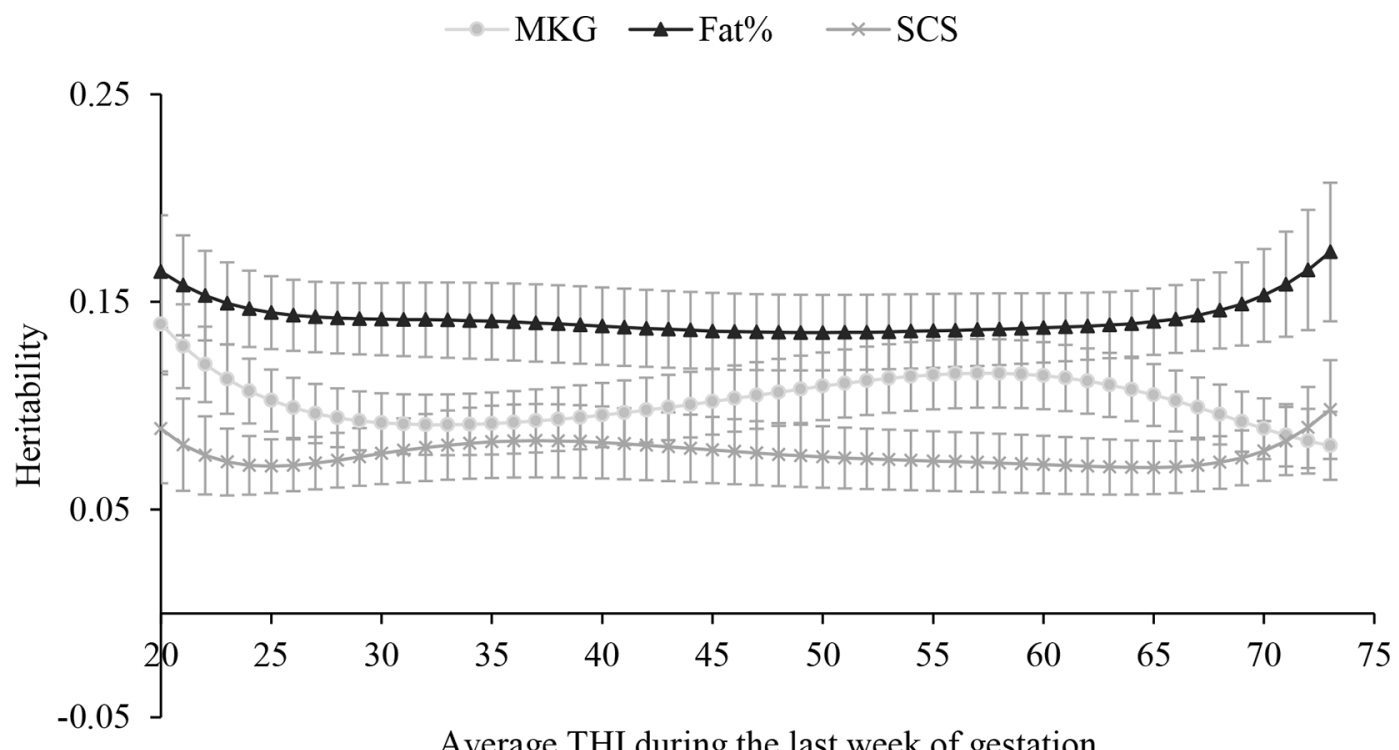

Figure 2. Posterior means for heritability estimates ( \pm posterior SD) for production traits of the first official test-day in first lactation [milk yield (MKG), fat percentage (fat\%), and SCS] by temperature-humidity index (THI) during the last week of gestation of the respective dam. 


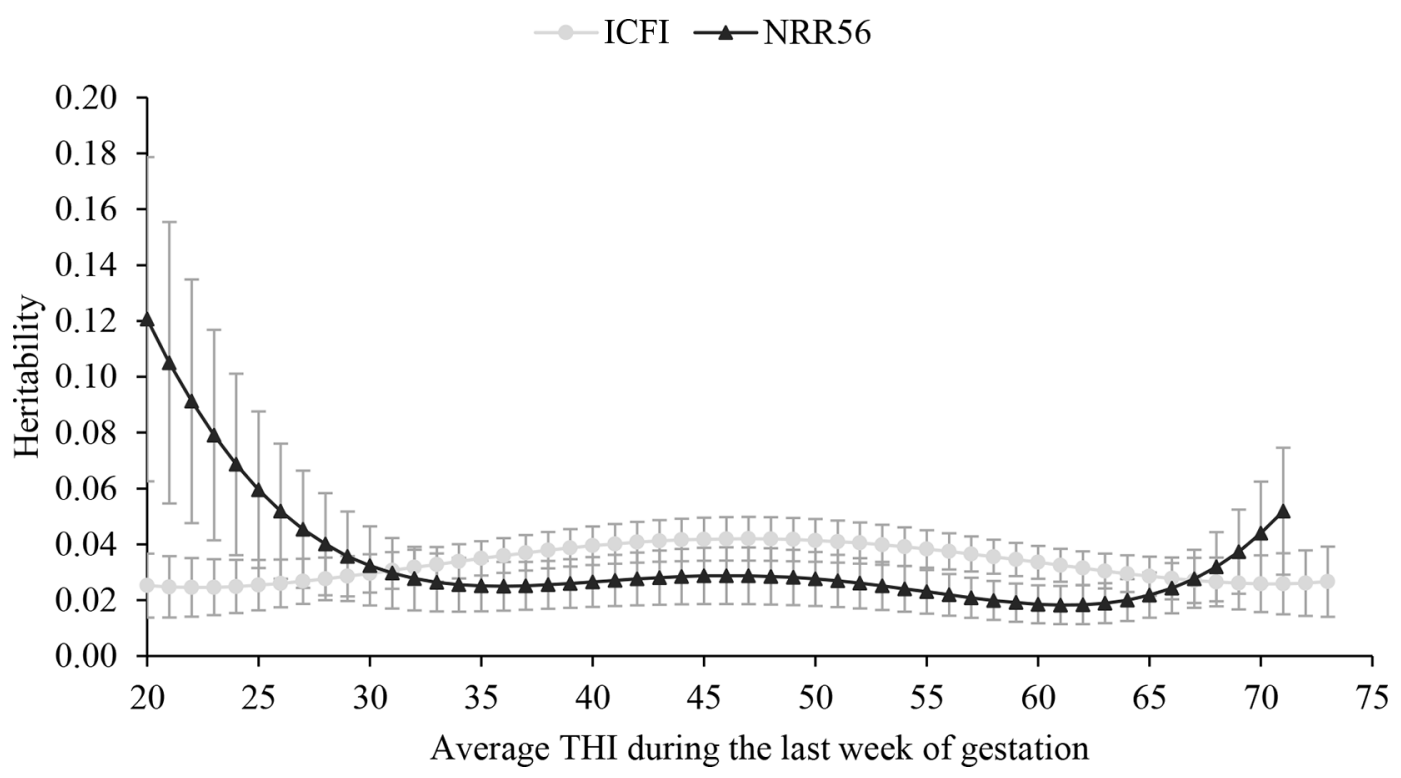

Figure 3. Posterior means for heritability estimates ( \pm posterior SD) for female fertility traits [nonreturn rate after $56 \mathrm{~d}(\mathrm{NRR} 56)$ in heifers and interval from calving to first insemination (ICFI) in first-parity cows] by temperature-humidity index (THI) during the last week of gestation of the respective dam.

correlation curve by time-lagged THI was wave-shaped, again displaying smallest estimates when correlating records from THI 65 with records from the extreme ends of the THI scale.

Figure 6 displays genetic correlations for female fertility traits between THI 65 and remaining THI. For NRR56, genetic correlations were in a wide range from 0.45 to 1 . The smallest genetic correlation $(0.45)$ was estimated for the most distanced THI combination including records from THI 20 and THI 65. However, especially for binary NNR56, smallest genetic correlations were associated with quite large posterior SD, up to 0.29 . For ICFI, genetic correlations were in a range from 0.81 to 1 , again displaying smallest estimates for most distanced THI.

Figure 7 displays the genetic correlations for the health traits across THI. Genetic correlations were smallest for the most distanced THI with 0.74 for MAST, 0.71 for DD, and 0.52 for EM. Again, also for the binary health traits and especially for EM, genetic correlation estimates between distant THI were associated with quite large posterior SD up to 0.22 .

\section{DISCUSSION}

\section{Heritabilities and Additive Genetic Variances by THI from Late Gestation}

Results from the present study indicate trait-specific effects of prenatal climate conditions during the last week of gestation on genetic parameters for production and for functional traits in the offspring generation. Increases of additive genetic variances and heritabilities in specific environments indicate a better genetic differentiation, and consequently improved accuracy of selection (Berry et al., 2011; Rahayu et al., 2015). Addressing several environmental and herd characteristics, Gernand et al. (2007) reported highest additive genetic variances and consequently superior selection environments in herds representing optimal feeding and husbandry conditions. With regard to prompt HS influence, Brügemann et al. (2011) identified decreasing genetic variances with increasing THI, and hypothesized suppression of the genetic potential in harsh environments. In contrast, Schierenbeck et al. (2011) argued that challenging environments might contribute to a pronounced genetic differentiation, as indicated by increasing SD for SCS yield deviations. Hence, different traits seem to react differently on environmental alterations, explaining trait-specific effects on (co)variance components under HS conditions.

Also from a time-lagged THI perspective as investigated in the present study, trait-specific changes of genetic parameters were observed. Smaller additive genetic variances and heritabilities for MKG and ICFI due to intrauterine HS indicate lower selection response. In contrast, for NRR56, MAST, DD, and EM, genetic variances and heritabilities increased in the range of high intrauterine THI, implying improved selection response in these traits for time-lagged HS. Similarly, for fat $\%$ and SCS, genetic variances and heritabilities increased slightly due to late gestation HS. The trait- 
specific alterations of additive genetic variances and heritabilities along the THI gradient make it difficult to give general recommendations for the optimal test environment of dry cows.

Heritability and additive genetic variance pattern for MKG and SCS by THI recorded during late gestation are in line with results by Bohlouli et al. (2019) for direct THI impact. Bohlouli et al. (2019) also found stronger variations of genetic variances and heritabilities across THI (observed THI period: $3 \mathrm{~d}$ before the test date) for MKG than for SCS. For low heritability health traits and for NRR56, the challenging HS environment for dry cows contributed to a pronounced genetic differentiation in offspring, but for MKG, temperate climate conditions for cows from THI 50 to THI 60 are favorable in this regard. In such context, Yin and König (2018) analyzed the effect of genetic, genomic, and phenotypic herd parameters. Interestingly, pattern of genetic parameters for low heritability traits along continuous herd gradients differed from genetic parameter pattern for moderate heritability production traits. However, RRM applications (especially models based on Legendre polynomials) were mostly associated with heritability and genetic variance fluctuations at both extreme ends of the continuous time or environmental scale, especially in the case of small data sets (e.g., Carabaño et al., 2007). To cope with this problem, we restricted the THI scale and eliminated extreme THI with a small number of trait records (less than 100 observations per THI). Nevertheless, for NRR56, DD, and EM, the "end-of-range" sensitivity (Meyer, 2005) might partly explain the increasing genetic variances and heritabilities at both extreme ends of the THI scale. Furthermore, quite large SD at the extreme ends of the THI scale for NRR56, DD, and EM indicate artifacts of RRM models.

In preliminary analyses using the same data, we applied the same model, but we ignored the random maternal component. Without modeling random maternal effects, heritabilities and additive genetic variances were slightly larger for all traits when compared with estimates from the current modeling approach. Hence, the maternal component may capture variance being associated with in utero HS. Generally, from a statistical modeling perspective, accounting for a further random component (i.e., the maternal effect), influences (co) variance components of remaining model effects. Deleterious maternal effects on the cow performance due to thermal stress imply a corresponding upgrade of the observed data due to the model adjustments. Hence, observed phenotypic differences among offspring will be lowered when applying the more sophisticated model including the maternal effects compared with a simpler model specification.

\section{Genotype x THI Interactions}

For NRR56 and the 3 health traits (MAST, DD, and EM), genetic correlations across THI were smaller than 0.80, indicating time-lagged $\mathrm{G} \times \mathrm{E}$ (Robertson, 1959). For the remaining traits (MKG, fat\%, SCS, and ICFI) and THI combinations, genetic correlations throughout

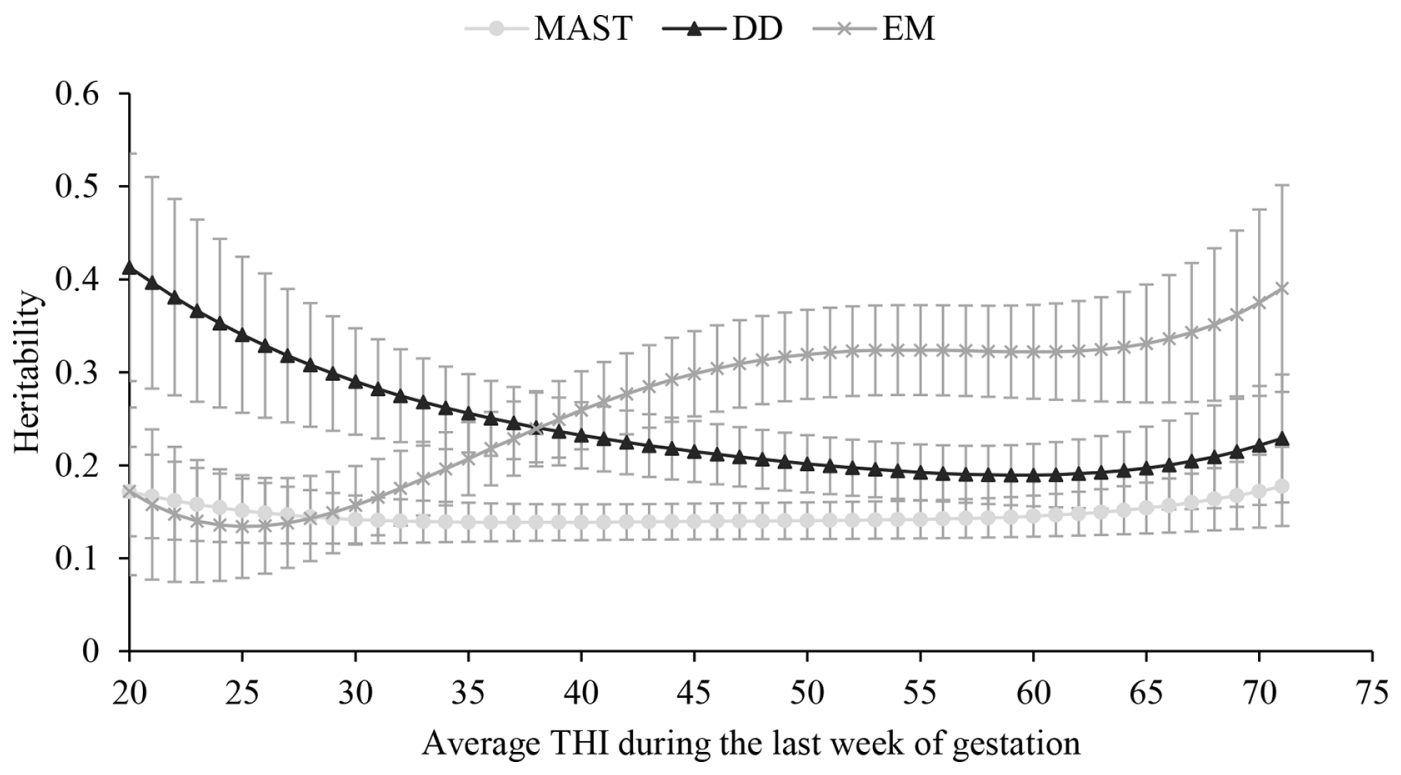

Figure 4. Posterior means for heritability estimates ( \pm posterior SD) for health traits in first-parity cows [clinical mastitis (MAST), digital dermatitis (DD), and endometritis (EM)] by temperature-humidity index (THI) during the last week of gestation of the respective dam. 


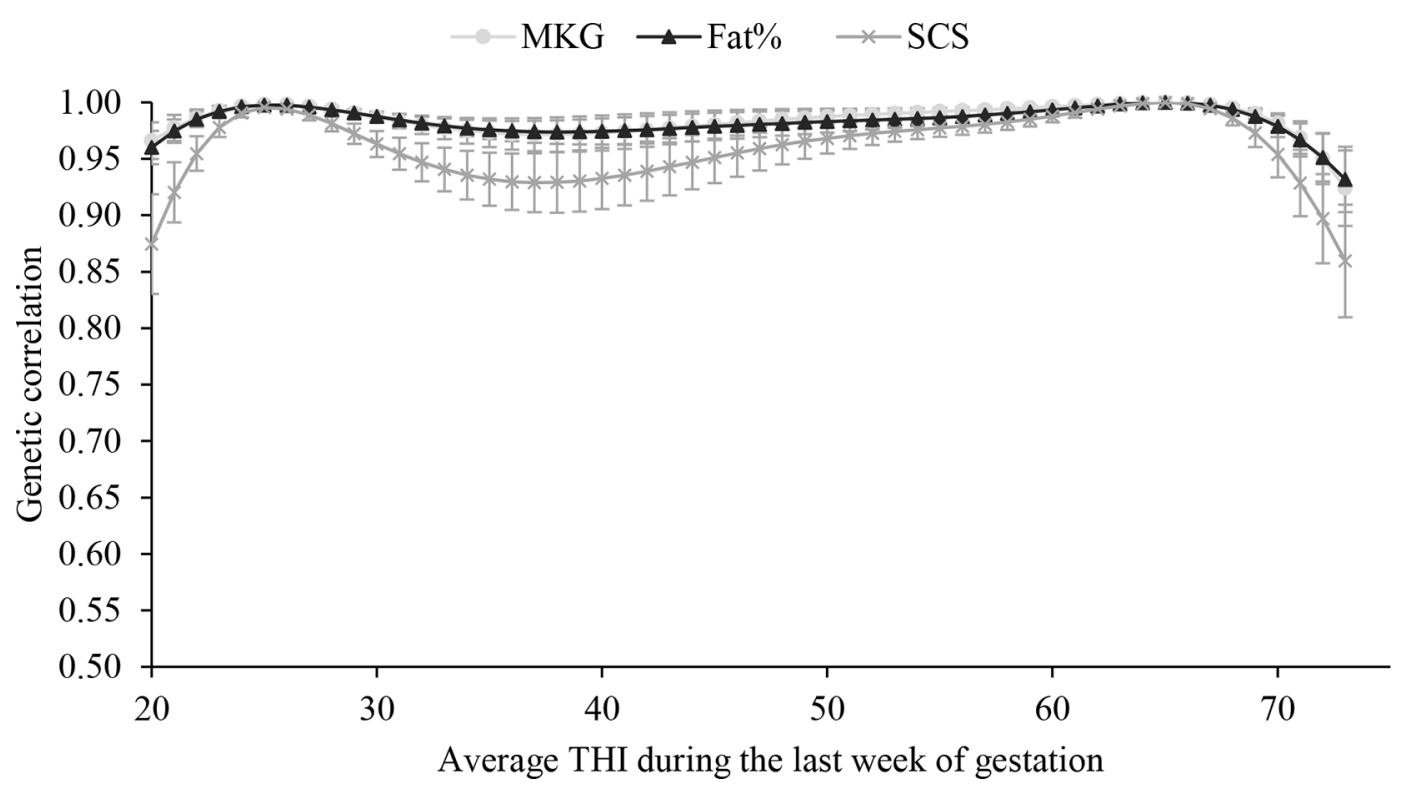

Figure 5. Posterior means for genetic correlations ( \pm posterior SD) of production traits of the first official test-day in first lactation $[$ milk yield (MKG), fat percentage (fat\%), and SCS] at temperature-humidity index (THI) of 65 with the same production trait at remaining THI during the last week of gestation of the respective dam.

larger than 0.80 disproved any $\mathrm{G} \times \mathrm{E}$. As expected from the genetic correlation estimates for NRR56, MAST, DD, and EM, pronounced fluctuations of sire EBV along the THI gradient were observed (results not shown). Alterations of EBV and low genetic correlations indicate that a superior fetus genotype growing optimally under thermoneutral prenatal conditions is hampered due to prenatal HS, and vice versa. This is of particular importance in the case of semen and embryo export in countries with tropical climates, which plays a major role for German breeding organizations (Yin et al., 2014; Al-Kanaan et al., 2015). Generally, genetic correlations between the same traits with respect to differing climatic prenatal conditions were smallest when THI were most distanced. Smallest genetic correlations when considering THI being far apart are in line with studies evaluating direct HS effects (e.g., Bradford et al., 2016; Santana et al., 2016). The largest THI distance was between THI 65 and THI 20, but similarly to cold stress impact, genetic correlations declined when considering the prenatal HS environment (THI >65).

In the present study, genetic correlations for production traits were throughout larger than 0.80 , but for the low heritability functional traits NRR56, MAST, DD, and $\mathrm{EM}$, indications for $\mathrm{G} \times \mathrm{E}$ were detected. Accordingly, for a broad pattern of environmental descriptors, Yin and König (2018) identified stronger environmental sensitivity and obvious $\mathrm{G} \times \mathrm{E}$ for low heritability functional traits than for moderate heritability production traits.
Studies with a focus on genotype by prenatal or early life environment interactions in agricultural livestock are rare. Nevertheless, some authors observed interactions between genotype and time-lagged environmental conditions during early life. In the crustacean Daphnia magna, Stjernman and Little (2011) reported genotype by maternal environment interaction for bacterial parasite susceptibility. Reifsnyder et al. (2000) identified interactions between genotypes and maternal postpartum environment for diabesity in mice and explained this with varying maternal milk composition. In humans, Wakschlag et al. (2010) reported interactions between genotype and prenatal exposure to cigarettes on adolescent behavior.

\section{Explanations for Time-Lagged HS Effect on Genetic Parameters}

In terms of direct $\mathrm{HS}$ effects, the explanation of $\mathrm{G}$ $\times \mathrm{E}$ addresses differences in gene activities and gene expressions in different environments such as "cold" and "hot" (Cammack et al., 2009). In the present study, HS occurred years before trait recording. In such time-lagged scenario across generations, epigenetic mechanisms may explain observed variations of genetic parameters and $\mathrm{G} \times$ E. Frésard et al. (2013) reviewed the effect of embryonic environment or early development on adult phenotype across generations in birds and mammals and discussed the potential of epigenetic factors in selection models. On a molecular 


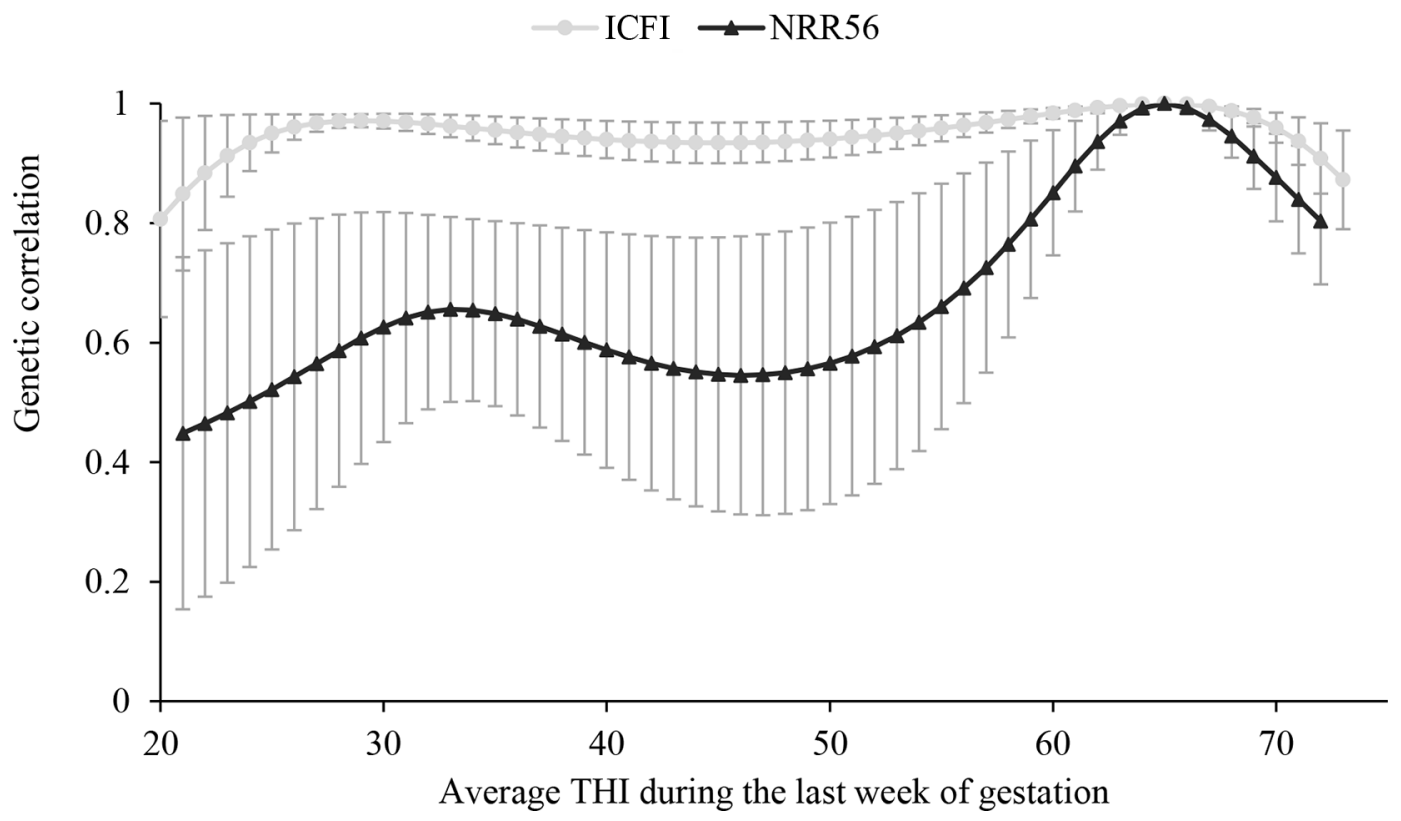

Figure 6. Posterior means for genetic correlations ( \pm posterior SD) of female fertility traits [nonreturn rate after $56 \mathrm{~d}$ (NRR56) in heifers and interval from calving to first insemination (ICFI) in first-parity cows] at a temperature-humidity index (THI) of 65 with the same female fertility trait at remaining THI during the last week of gestation of the respective dam.

level, prenatal environmental factors including (heat) stress, nutrition, diseases or toxins caused epigenetic modifications (DNA methylation and histone modification) in the genome of the fetus, with influence on gene expressions after birth and during aging (Funston and Summers, 2013). Epigenetic modifications can be transmitted to daughter cells (Singh et al., 2012), with long-lasting influence in growing and in adult animals. For example, Li et al. (2004) reported that prenatal hypoxia causes in utero programming of the $h s p 70$ gene in the rat heart, resulting in reduced HS reactions in adulthood. Hypoxia can be caused by maternal HS in

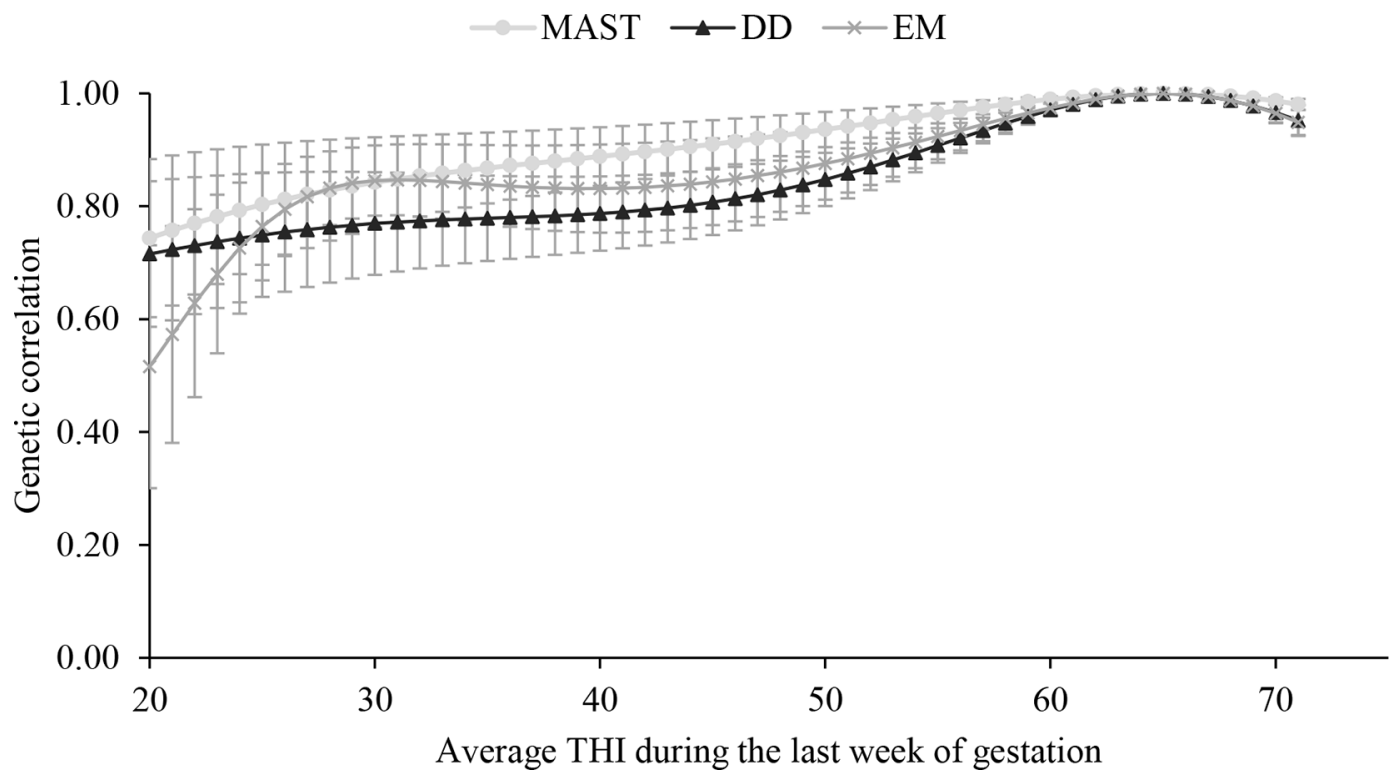

Figure 7. Posterior means for genetic correlations ( \pm posterior SD) of health traits in first-parity cows [clinical mastitis (MAST), digital dermatitis (DD), and endometritis (EM)] at a temperature-humidity index (THI) of 65 with the same health trait at remaining THI during the last week of gestation of the respective dam. 
the fetus (Leos et al., 2010). Zhu et al. (2008) observed methylation imprinting changes in mice embryos due to HS. Those epigenetic modifications led to embryonic developmental failure. Also in dairy cattle, there is evidence that prenatal $\mathrm{HS}$ during the last $46 \mathrm{~d}$ of gestation modified DNA methylation and gene expressions of the liver and the mammary gland in calves and heifers (Skibiel et al., 2018). The affected genes are involved in physiological functions such as cell signaling and cell cycle, in innate immune defense, and in enzyme activations (Skibiel et al., 2018). Thus, we postulate that epigenetic modifications of the genome structure triggered by HS events during the last week of gestation, are persistent with effects on traits recorded late in life. However, the underlying epigenetic mechanisms should be inferred in molecular experiments, but timelagged alterations are a first hint in this regard.

\section{CONCLUSIONS}

To the best of our knowledge, this is the first study analyzing the effect of intrauterine HS on genetic parameters of production and functional traits from an across-generation perspective in Holstein Friesian cows. Additive genetic variances and heritability estimates for traits recorded in the offspring generation were altered by THI during late gestation of their dams. Because of trait-specific alterations along the THI gradient, no general recommendations for the optimal dry cow environment can be made. For the low heritability functional traits NRR56, MAST, DD, and EM, we identified genotype $\times$ intrauterine HS interactions, implying re-rankings of sires according to their differing EBV across prenatal THI conditions. Selection of thermotolerant animals with stable EBV, independent from time-lagged environmental impact, can prevent genotype by HS interactions in offspring generations.

\section{ACKNOWLEDGMENTS}

The authors gratefully acknowledge the support of the "H. Wilhelm Schaumann Stiftung" (Hamburg, Germany) for providing a scholarship to Cordula Kipp. The authors gratefully acknowledge the financial support provided by the German Research Foundation (DFG, Bonn, Germany) through grant number KO 3520/8-1. The authors have not stated any conflicts of interest.

\section{REFERENCES}

Aguilar, I., I. Misztal, and S. Tsuruta. 2009. Genetic components of heat stress for dairy cattle with multiple lactations. J. Dairy Sci. 92:5702-5711. https://doi.org/10.3168/jds.2008-1928.
Al-Kanaan, A., S. König, and K. Brügemann. 2015. Effects of heat stress on semen characteristics of Holstein bulls estimated on a continuous phenotypic and genetic scale. Livest. Sci. 177:15-24. https://doi.org/10.1016/j.livsci.2015.04.003.

Ali, A. K. A., and G. E. Shook. 1980. An optimum transformation for somatic cell concentration in milk. J. Dairy Sci. 63:487-490. https: //doi.org/10.3168/jds.S0022-0302(80)82959-6.

Bell, A. W., B. W. McBride, R. Slepetis, R. J. Early, and W. B. Currie. 1989. Chronic heat stress and prenatal development in sheep: I. Conceptus growth and maternal plasma hormones and metabolites. J. Anim. Sci. 67:3289-3299. https://doi.org/10.2527/jas1989 $.67123289 x$.

Berry, D. P., M. L. Bermingham, M. Good, and S. J. More. 2011. Genetics of animal health and disease in cattle. Ir. Vet. J. 64:5. https: //doi.org/10.1186/2046-0481-64-5.

Bohlouli, M., S. Alijani, S. Naderi, T. Yin, and S. König. 2019. Prediction accuracies and genetic parameters for test-day traits from genomic and pedigree-based random regression models with or without heat stress interactions. J. Dairy Sci. 102:488-502. https:/ /doi.org/10.3168/jds.2018-15329.

Bradford, H. L., B. O. Fragomeni, J. K. Bertrand, D. A. L. Lourenco, and I. Misztal. 2016. Genetic evaluations for growth heat tolerance in Angus cattle. J. Anim. Sci. 94:4143-4150. https://doi.org/10 $.2527 /$ jas.2016-0707.

Brügemann, K., E. Gernand, U. U. von Borstel, and S. König. 2011. Genetic analyses of protein yield in dairy cows applying random regression models with time-dependent and temperature $\mathrm{x}$ humidity-dependent covariates. J. Dairy Sci. 94:4129-4139. https://doi .org/10.3168/jds.2010-4063.

Cammack, K. M., E. Antoniou, L. Hearne, and W. R. Lamberson. 2009. Testicular gene expression in male mice divergent for fertility after heat stress. Theriogenology 71:651-661. https://doi.org/ 10.1016/j.theriogenology.2008.09.029.

Carabaño, M. J., C. Díaz, C. Ugarte, and M. Serrano. 2007. Exploring the use of random regression models with Legendre polynomials to analyze measures of volume of ejaculate in Holstein bulls. J. Dairy Sci. 90:1044-1057. https://doi.org/10.3168/jds.S0022 -0302(07)71591-6.

Chen, X., A. L. Fahy, A. S. Green, M. J. Anderson, R. P. Rhoads, and S. W. Limesand. 2010. $\beta 2$-Adrenergic receptor desensitization in perirenal adipose tissue in fetuses and lambs with placental insufficiency-induced intrauterine growth restriction. J. Physiol. 588:3539-3549. https://doi.org/10.1113/jphysiol.2010.192310.

De Vries, M. J., S. M. van der Beek, L. M. T. E. Kaal-Lansbergen, W. Ouweltjes, and J. B. M. Wilmink. 1999. Modeling of energy balance in early lactation and the effect of energy deficits in early lactation on first detected estrus postpartum in dairy cows. J. Dairy Sci. 82:1927-1934. https://doi.org/10.3168/jds.S0022 -0302(99)75428-7.

Faurie, A. S., D. Mitchell, and H. P. Laburn. 2001. Feto-maternal relationships in goats during heat and cold exposure. Exp. Physiol. 86:199-204. https://doi.org/10.1113/eph8602152.

Frésard, L., M. Morisson, J. M. Brun, A. Collin, B. Pain, F. Minvielle, and F. Pitel. 2013. Epigenetics and phenotypic variability: Some interesting insights from birds. Genet. Sel. Evol. 45:16. https://doi .org/10.1186/1297-9686-45-16.

Funston, R. N., and A. F. Summers. 2013. Epigenetics: setting up lifetime production of beef cows by managing nutrition. Annu. Rev. Anim. Biosci. 1:339-363. https://doi.org/10.1146/annurev-animal -031412-103649.

Gernand, E., S. König, and C. Kipp. 2019. Influence of on-farm measurements for heat stress indicators on dairy cow productivity, female fertility, and health. J. Dairy Sci. 102:6660-6671. https:// doi.org/10.3168/jds.2018-16011.

Gernand, E., R. Waßmuth, U. U. von Borstel, and S. König. 2007. Heterogeneity of variance components for production traits in large-scale dairy farms. Livest. Sci. 112:78-89. https://doi.org/10 .1016/j.livsci.2007.01.157.

Hay, E. H., and A. Roberts. 2018. Genotype $\times$ prenatal and postweaning nutritional environment interaction in a composite beef 
cattle breed using reaction norms and a multi-trait model. J. Anim. Sci. 96:444-453. https://doi.org/10.1093/jas/skx057.

Heijmans, B. T., E. W. Tobi, A. D. Stein, H. Putter, G. J. Blauw, E. S. Susser, P. E. Slagboom, and L. H. Lumey. 2008. Persistent epigenetic differences associated with prenatal exposure to famine in humans. Proc. Natl. Acad. Sci. USA 105:17046-17049. https:// doi.org/10.1073/pnas.0806560105.

Hijmans, R. J., E. Williams, C. Vennes, and M. R. J. Hijmans. 2016. Package 'geosphere'. Accessed Nov. 19, 2017. https://cran.r -project.org/web/packages/geosphere/index.html.

Kipp, C., K. Brügemann, P. Zieger, K. Mütze, S. Möcklinghoff-Wicke, S. König, and K. Halli. 2021. Across-generation effects of maternal heat stress during late gestation on production, female fertility and longevity traits in dairy cows. J. Dairy Res. 1-7. https://doi.org/ 10.1017/S0022029921000327.

Laporta, J., F. C. Ferreira, V. Ouellet, B. Dado-Senn, A. K. Almeida, A. de Vries, and G. E. Dahl. 2020. Late-gestation heat stress impairs daughter and granddaughter lifetime performance. J. Dairy Sci. 103:7555-7568. https://doi.org/10.3168/jds.2020-18154.

Leos, R. A., M. J. Anderson, X. Chen, J. Pugmire, K. A. Anderson, and S. W. Limesand. 2010. Chronic exposure to elevated norepinephrine suppresses insulin secretion in fetal sheep with placental insufficiency and intrauterine growth restriction. Am. J. Physiol. Endocrinol. Metab. 298:E770-E778. https://doi.org/10.1152/ ajpendo.00494.2009.

Li, G., S. Bae, and L. Zhang. 2004. Effect of prenatal hypoxia on heat stress-mediated cardioprotection in adult rat heart. Am. J. Physiol. Heart Circ. Physiol. 286:H1712-H1719. https://doi.org/ 10.1152/ajpheart.00898.2003.

Madsen, P., and J. Jensen. 2013. A user's guide to DMU. A package for analysing multivariate mixed models. Version 6 , release 5.2. Center for Quantitative Genetics and Genomics. Dept. of Molecular Biology and Genetics, University of Aarhus, Research Centre Foulum.

Menéndez-Buxadera, A., R. J. Pereira, L. El Faro, and M. L. Santana Jr.. 2020. Genotype by environment interaction due to heat stress during gestation and postpartum for milk production of Holstein cattle. Animal 14:2014-2022. https://doi.org/10.1017/ S1751731120001068.

Meyer, K. 2005. Random regression analyses using B-splines to model growth of Australian Angus cattle. Genet. Sel. Evol. 37:473-500. https://doi.org/10.1186/1297-9686-37-6-473.

Monteiro, A. P. A., S. Tao, I. M. T. Thompson, and G. E. Dahl. 2016. In utero heat stress decreases calf survival and performance through the first lactation. J. Dairy Sci. 99:8443-8450. https://doi .org/10.3168/jds.2016-11072.

NRC. 1971. A Guide to Environmental Research on Animals. Natl. Acad. Sci.

Oseni, S., I. Misztal, S. Tsuruta, and R. Rekaya. 2003. Seasonality of days open in US Holsteins. J. Dairy Sci. 86:3718-3725. https://doi .org/10.3168/jds.S0022-0302(03)73977-0.

Rahayu, A. P., S. Johari, and E. Kurnianto. 2015. Genetic gains of milk yield and milk composition as realized response to dairy cow selection in Bbptu-hpt Baturraden, Indonesia. J. Indones. Trop. Anim. Agric. 40:79-86. https://doi.org/10.14710/jitaa.40.2.79-86.

Regnault, T. R. H., B. de Vrijer, H. L. Galan, R. B. Wilkening, F. C. Battaglia, and G. Meschia. 2007. Development and mechanisms of fetal hypoxia in severe fetal growth restriction. Placenta 28:714723. https://doi.org/10.1016/j.placenta.2006.06.007.

Reifsnyder, P. C., G. Churchill, and E. H. Leiter. 2000. Maternal environment and genotype interact to establish diabesity in mice. Genome Res. 10:1568-1578. https://doi.org/10.1101/gr.147000.
Robertson, A. 1959. The sampling variance of the genetic correlation coefficient. Biometrics 15:469-485. https://doi.org/10.2307/ 2527750 .

Santana, M. L. Jr., A. B. Bignardi, R. J. Pereira, A. Menéndez-Buxadera, and L. El Faro. 2016. Random regression models to account for the effect of genotype by environment interaction due to heat stress on the milk yield of Holstein cows under tropical conditions. J. Appl. Genet. 57:119-127. https://doi.org/10.1007/s13353-015 -0301-x.

Schierenbeck, S., F. Reinhardt, R. Reents, H. Simianer, and S. König. 2011. Identification of informative cooperator herds for progeny testing based on yield deviations. J. Dairy Sci. 94:2071-2082. https://doi.org/10.3168/jds.2010-3466.

Shabalina, T., T. Yin, and S. König. 2020. Influence of common health disorders on the length of productive life and stayability in German Holstein cows. J. Dairy Sci. 103:583-596. https://doi.org/10 $.3168 /$ jds.2019-16985.

Singh, K., A. J. Molenaar, K. M. Swanson, B. Gudex, J. A. Arias, R. A. Erdman, and K. Stelwagen. 2012. Epigenetics: A possible role in acute and transgenerational regulation of dairy cow milk production. Animal 6:375-381. https://doi.org/10.1017/ S1751731111002564.

Skibiel, A. L., F. Peñagaricano, R. Amorín, B. M. Ahmed, G. E. Dahl, and J. Laporta. 2018. In utero heat stress alters the offspring epigenome. Sci. Rep. 8:14609. https://doi.org/10.1038/s41598-018 $-32975-1$.

Stjernman, M., and T. J. Little. 2011. Genetic variation for maternal effects on parasite susceptibility. J. Evol. Biol. 24:2357-2363. https://doi.org/10.1111/j.1420-9101.2011.02363.x.

Stock, K. F., J. Cole, J. Pryce, N. Gengler, A. Bradley, L. Andrews, B. Heringstad, and C. Egger-Danner. 2013. Standardization of health data-ICAR guidelines including health key. ICAR Tech. Ser. 17:75-81.

Tao, S., and G. E. Dahl. 2013. Invited review: Heat stress effects during late gestation on dry cows and their calves. J. Dairy Sci. 96:4079-4093. https://doi.org/10.3168/jds.2012-6278.

Tao, S., A. P. A. Monteiro, M. J. Hayen, and G. E. Dahl. 2014. Short communication: Maternal heat stress during the dry period alters postnatal whole-body insulin response of calves. J. Dairy Sci. 97:897-901. https://doi.org/10.3168/jds.2013-7323.

Tao, S., A. P. A. Monteiro, I. M. Thompson, M. J. Hayen, and G. E. Dahl. 2012. Effect of late-gestation maternal heat stress on growth and immune function of dairy calves. J. Dairy Sci. 95:7128-7136. https://doi.org/10.3168/jds.2012-5697.

Wakschlag, L. S., E. O. Kistner, D. S. Pine, G. Biesecker, K. E. Pickett, A. D. Skol, V. Dukic, R. J. Blair, B. L. Leventhal, N. J. Cox, J. L. Burns, K. E. Kasza, R. J. Wright, and E. H. Cook Jr.. 2010. Interaction of prenatal exposure to cigarettes and MAOA genotype in pathways to youth antisocial behavior. Mol. Psychiatry 15:928-937. https://doi.org/10.1038/mp.2009.22.

Yin, T., and S. König. 2018. Heritabilities and genetic correlations in the same traits across different strata of herds created according to continuous genomic, genetic, and phenotypic descriptors. J. Dairy Sci. 101:2171-2186. https://doi.org/10.3168/jds.2017-13575.

Yin, T., E. C. G. Pimentel, U. U. König von Borstel, and S. König. 2014. Strategy for the simulation and analysis of longitudinal phenotypic and genomic data in the context of a temperature $x$ humidity-dependent covariate. J. Dairy Sci. 97:2444-2454. https:/ /doi.org/10.3168/jds.2013-7143.

Zhu, J. Q., J. H. Liu, X. W. Liang, B. Z. Xu, Y. Hou, X. X. Zha, and Q. Y. Sun. 2008. Heat stress causes aberrant DNA methylation of H19 and Igf-2r in mouse blastocysts. Mol. Cells 25:211-215. 